\title{
Estimating Regional Capital Stocks
}

\author{
Timothy L. Hunt*
}

\section{INTRODUCTION}

Even though the true stock of capital is not directly observable, capital stock estimates are needed for production functions, cost and profit functions, growth theory, and interregional trade theory. The alternative is to make heroic assumptions concerning proportionality relationships between capital and other variables or strong equilibrium assumptions such as equalization of returns to capital across regions. ${ }^{1}$ However necessary or appropriate these assumptions may have been in the past, the development of disequilibrium models, flexible functional forms, ${ }^{2}$ and interest in adding natural resources such as energy to economic models have dictated that capital stocks must be estimated directly as part of the model itself. Indeed, Miernyk [8] in a commentary on recent regional growth theories notes that one of the reasons that Richardson's regional growth model [13] remains statistically untestable is the lack of regional data on capital stocks.

The purpose of this paper is to statistically compare the two methods which have been used to estimate regional capital stocks, namely book value and the perpetual inventory method (hereafter BV and PIM respectively). Examples of the former include Winkler [17] in this Review and others such as Lande and Gordon [7], Vinod [16], Moroney [9], and Moroney and Walker [10]. Examples of the latter include Field and Grebenstein [2], Persky [11], and Persky and Klein [12].

The empirical test of this study uses data for U. S. manufacturing in 1976 with states as the unit of observation. The major conclusion is that the variation in BV and PIM estimates of the capital stock by state for manufacturing in 1976 are virtually indistinguishable from each other. Though this result does not directly prove that the same association exists for particular industries, for regions smaller than states, or for nonmanufacturing, it does suggest that $\mathrm{BV}$ is a valid proxy for the capital stock. This finding is significant in that the data requirements for the PIM estimates of the capital stock virtually preclude their use in most regional studies, whereas BV may be available directly or through primary data collection.

\footnotetext{
* Senior Research Economist, W. E. Upjohn Institute for Employment Research, Kalamazoo, Michigan. The research for this paper was conducted while the author was on the faculty at Kansas State University, Manhattan, Kansas.
} 


\section{METHODOLOGY}

The true economic stock of capital in today's prices is unknown because of its heterogeneous nature, its durability, and the lack of secondary markets to establish current prices. Other problems in estimating the stock of capital include significant questions about technical embodiment, spatial dispersion of new technology, and utilization rates of the existing stock of capital. Suffice it to say that either BV or PIM estimates of the capital stock are at best only crude estimates or proxies for the true but unknown stock of capital.

$\mathrm{BV}$ is the total acquisition cost at purchase year prices of all structures and equipment on the books of firms at the end of a year [14]. Its advantage is that it is a direct and readily available measure of the capital stock. However, since $\mathrm{BV}$ is stated on an original cost basis, there is no adjustment for inflation, and no such adjustment is possible due to the lack of information about the year of purchase for the components of that stock. If a region such as New England contains predominantly old capital, then BV may seriously understate the stock of capital, particularly given the high inflation rates of the 1970's. Thus, the primary weakness of BV as a measure of the value of the capital stock is its failure to price that stock in today's prices or some constant dollar equivalent thereof.

PIM estimates of the capital stock, on the other hand, resolve the problem of pricing the capital stock and in so doing develop a more viable measure of the economic stock of capital. ${ }^{3}$ The basic relationship is

(1) $\mathrm{K}_{\mathrm{t}}=\mathrm{PI}_{\mathrm{t}}^{-1} \mathrm{I}_{\mathrm{t}}+(1-\mathrm{d}) \mathrm{K}_{\mathrm{t}-1}$

where

$$
\begin{aligned}
\mathrm{K}_{\mathrm{t}} & =\text { stock of capital in year } \mathrm{t} \\
\mathrm{PI}_{\mathrm{t}} & =\text { price index for investment goods in year } \mathrm{t}(\text { base }=1.0) \\
\mathrm{I}_{\mathrm{t}} & =\text { gross investment in year } \mathrm{t} \\
\mathrm{d} & =\text { constant depreciation rate }
\end{aligned}
$$

If sufficient historical data are available for the price index ${ }^{4}$ and gross investment series, then the current capital stock can be found by iteration of (1) given some value for the depreciation rate, d. Furthermore, the existence of a capital benchmark allows the iteration process to begin in that year.

The determination of the appropriate rate of depreciation may be troublesome, but tax information, industry surveys, and expert opinion may provide an approximation of $d$. The assumption that $d$ is constant over time is based on the belief that given the stock nature of capital such rates will change only slowly and the fact that a constant $d$ greatly simplifies the calculations by avoiding direct dating of the stock. The additional assumption that $\mathrm{d}$ is constant across regions is necessitated by the lack of information about spatial variation in depreciation rates. If $\mathrm{d}$ actually varies across regions, then the PIM estimates of regional capital stocks are biased by this spatial variation in 
d. In contrast, notice that BV is not subject to this criticism since it is a direct measure that allows for spatial variation.

In short, PIM develops more viable estimates of the economic stock of capital, but there is a cost involved in that the depreciation rate itself must be determined and that estimated rate is assumed constant over time and across regions. Furthermore, there remains for the regional economist the very practical problem that sufficient historical data are not usually available to construct PIM estimates of the capital stock. Thus, it is an appropriate empirical question to determine the statistical correlation of BV and PIM estimates of the capital stock.

$A$ priori it is reasonable to expect BV and PIM estimates of the capital stock to be positively correlated. However, it is important to note that BV information is collected directly from businesses as part of the surveys of the Bureau of the Census, ${ }^{5}$ while PIM estimates are constructed from gross investment data. To the extent that BV is subject to the inflationary bias discussed earlier or the PIM estimates are biased by spatial variation in the rate of depreciation, then that correlation will be lowered unless the two effects are somehow offsetting. This latter possibility is considered highly unlikely, though unexplored in the current study.

\section{EMPIRICAL TEST}

BV and PIM estimates of the capital stock for manufacturing are compared for a cross-section of states in 1976 . BV by state was obtained directly from the Annual Survey of Manufactures [14] for 1976. The perpetual inventory estimates were constructed as follows.

First, the rate of depreciation was estimated as the mean rate implicit in the national capital stock estimates for U.S. manufacturing, 1958-76. ${ }^{6}$ Solving (1) for $\mathrm{d}$, then

$$
\text { (2) } d=1-\frac{K_{t}-I_{t}}{K_{t-1}}
$$

where specifically $\mathrm{K}$ is the constant dollar net stock of capital for manufacturing [15], and I is new capital expenditures for manufacturing [14] deflated by the price index for nonresidential investment [15]. ${ }^{7}$ The estimated mean depreciation rate was .1085 with a standard error of .0025 . As expected, the rate appears quite stable based upon its low variance.

Second, 1957 was chosen as the base year to begin the calculations for the PIM estimates of the capital stock by state because of the complete BV information available in that year in the Survey of Manufactures [14]. Although the benchmark year uses BV information, less than 13 percent of the original 1957 capital stock estimates remain available in 1976 and thus do not significantly upward bias the correlation of the PIM estimates in 1976 with BV in the same year. 
The price index for nonresidential investment was set equal to 1.0 in 1976 , and the investment data for each state, 1958-76, are from the various editions of the Census of Manufactures and its annual supplements [14]. In brief, iteration of (1) using the estimated depreciation rate and the referenced data yields the PIM estimate of the capital stock in 1976 in current dollars for a particular state, and the procedure is repeated for all 48 states. $^{8}$

The simple correlation of book value and the PIM estimates of the capital stock by state in 1976 for manufacturing is $.9942 .{ }^{9}$ Apparently the variation across states in 1976 in book value and the PIM estimates of the capital stock are almost identical. To determine the difference in absolute levels between the two variables, the no intercept regression of BV on the PIM estimates was used; it was found that BV is .741 of the PIM estimate of the capital stock with a standard error of .0085. It should not be surprising that BV is smaller absolutely than the PIM estimates since BV is not stated in terms of today's higher prices.

\section{CONCLUSIONS}

The major conclusion of this study is that the variation across states in BV and the PIM estimates for U.S. manufacturing in 1976 are very similar. Perhaps the high correlation coefficient is somewhat surprising in that the BV estimates are a direct original cost measure while the PIM estimates are stated in today's prices assuming a constant depreciation rate. In any case, there is no evidence in this study that depreciation rates vary across regions or that the data on BV are biased by the existence of predominantly old capital regions.

The primary significance of these findings for regional analysis is that BV appears to be a valid proxy for regional capital stocks, differing only from the PIM estimates by a multiplicative constant less than one which can be estimated from aggregate data, if needed. Due to the paucity of regional data, such a finding is heartening indeed.

\section{FOOTNOTES}

1. For an example of this latter approach see Kraft and Kraft [6, p. 97] in this Review.

2. A functional form is flexible if it does not $a$ priori constrain the price and income elasticities. See Fuss, McFadden, and Mundlak [3, pp. 230-240].

3. The perpetual inventory method was popularized by Goldsmith [4].

4. Data limitations necessitate the use of national price indices.

5. The survey forms actually used can be found in the 1972 edition of the Census of Manufactures [14].
6. This procedure follows Berndt and Christensen [1, p. 106].

7. The capital stock estimates so obtained and used throughout this study are clearly net estimates. Kendrick and Lee [5] show that PIM estimates may be obtained for either net or gross stocks of capital.

8. The sample included the continental United States excluding the District of Columbia.

9. The Spearman rank correlation was .9945.

\section{REFERENCES}

1. Berndt, Ernst R. and Lauritis R. Christensen. "The Translog Function and the Substitution of Equipment, Structures, and Labor in U. S.
Manufacturing." Journal of Econometrics, (January 1973), 81-114.

2. Field, Barry C. and Charles Grebenstein. 
"Capital-Energy Substitution in U.S. Manufacturing," University of Massachusetts, Review of Economics and Statistics (May 1980), 207-212.

3. Fuss, Melvyn, Daniel McFadden, and Yair Mundlak. "A Survey of Functional Forms in the Economic Analysis of Production." Production Economics: A Dual Approach to Theory and Applications, Vol. 1 Melvyn Fuss and Daniel McFadden, eds. Amsterdam: NorthHolland Publishing Co., 1978, pp. 219-268.

4. Goldsmith, Raymond W. A Study of Saving in the United States. Princeton: Princeton University Press, 1955.

5. Kendrick, John W. and Kyu Sik Lee. "Quarterly Estimates of Capital Stocks in the U.S. Private Domestic Economy, by Major Industry Groups." Review of Income and Wealth, (December 1976), 345-352.

6. Kraft, John and Arthur Kraft. "Comparison of Regional Elasticities of Substitution: North versus South." Review of Regional Studies, (Supplement 1974), 95-100.

7. Lande, Paul S. and Peter Gordon. "Regional Growth in the United States: A Reexamination of the Neoclassical Model." Journal of Regional Science (April 1977), 61-69.

8. Miernyk, William H. "A Note on Recent Regional Growth Theories." Journal of
Regional Science, (August 1979), 303-308.

9. Moroney, John R. "The Strong-Factor-Intensity Hypothesis A Multisectoral Test." Journal of Political Economy, (June 1967), 241-249.

10. , and James M. Walker. "A

Regional Test of the Heckscher-Ohlin Hypothesis." Journal of Political Economy, (December 1966), 573-586.

11. Persky, Joseph. "Dualism, Capital-Labor Ratios and the Regions of the U.S." Journal of Regional Science, (December 1978), 373-382.

12. , and Walter Klein. "Regional Capital Growth and Some of Those Other Things We Never Talk About." Papers, Regional Science Association, (1975), 181-190.

13. Richardson, Harry W. Regional Growth Theory. London: Macmillan Co., 1973.

14. U.S. Department of Commerce, Bureau of Census. Census of Manufacturers and Annual Survey of Manufactures, various issues.

15. U.S. Department of Commerce, Bureau of Economic Analysis. Survey of Current Business, various issues.

16. Vinod, H. D. "Interregional Comparison of Production Structures." Journal of Regional Science, (August 1973), 261-267.

17. Winkler, Albert L. "Interregional Variations in Manufacturing Investment." Review of Regional Studies, (Fall 1977), 37-51. 